\title{
СОВЕРШЕНСТВОВАНИЕ СИСТЕМЫ ИПОТЕЧНОГО ЖИЛИЩНОГО КРЕДИТОВАНИЯ КАК ФАКТОРА УСТОЙЧИВОГО РАЗВИТИЯ НАЦИОНАЛЬНОЙ ЭКОНОМИКИ
}

\author{
(C) 2019 Иванова Дарья Геннадьевна \\ кандидат экономических наук, доцент кафедры «Мировой экономики» \\ Ростовский государственный экономический университет, Россия, Ростов-на-Дону \\ E-mail: ivanova753@yandex.ru
}

В статье раскрыты основные направления совершенствования ипотечного жилищного кредитования в контексте концепции устойчивого развития. Рассмотрены модели организации ипотечного жилищного кредитования и возможности их применения в России, а также проведен анализ ипотечного рынка Ростовской области.

Ключевые слова: ипотечное жилищное кредитование, устойчивое развитие, модели ипотечного кредитования, региональный ипотечный рынок.

Концепцией долгосрочного социально-экономического развития Российской Федерации на период до 2020 года в качестве одной из ключевых государственных задач рассматривается обеспечение устойчивого развития национальной экономики, одним из факторов которого выступает ипотечное кредитование.

В мировой практике формы ипотечного жилищного кредитования, применяемые в разных странах, имеют особенности, обусловленные национальными, региональными, историческими факторами, а также особенностями правовой и финансовой системы. В.А. Савинова выделяет две функционирующие модели ипотечного жилищного кредитования, различающиеся способами привлечения финансовых ресурсов, инфраструктурой и степенью государственного регулирования: одноуровневую (европейскую или немецкую) модель и двухуровневую (универсальную или американскую) модель ипотечного жилищного кредитования.

Двухуровневая модель организации ипотеч- ного жилищного кредитования была создана и получила наибольшее развитие в США. Это схема, в основе которой применение закладных, ценных бумаг и недвижимости (см. рисунок 1).

Заемщик приобретает готовое жилье, как правило, оплачивая при этом лишь небольшую часть его стоимости наличными, а всю оставшуюся сумму - заемными деньгами специализированного ипотечного банка. Ссуды, которые выдаются банком, объединяются в пакеты ипотеки и продаются внешним инвесторам, а вырученные от продажи деньги снова пускаются в оборот, тем самым начиная новый цикл кредитования. Государство через специальные компании выкупает закладные по кредитам, и, выступая гарантом по ценным бумагам ипотеки, продает их инвестору, который получает по ним небольшой постоянный доход.

Основными участниками американской модели ипотечного кредитования являются: заемщик, приобретающий кредит на покупку жилья; банк-кредитор, предоставляющий заемщику

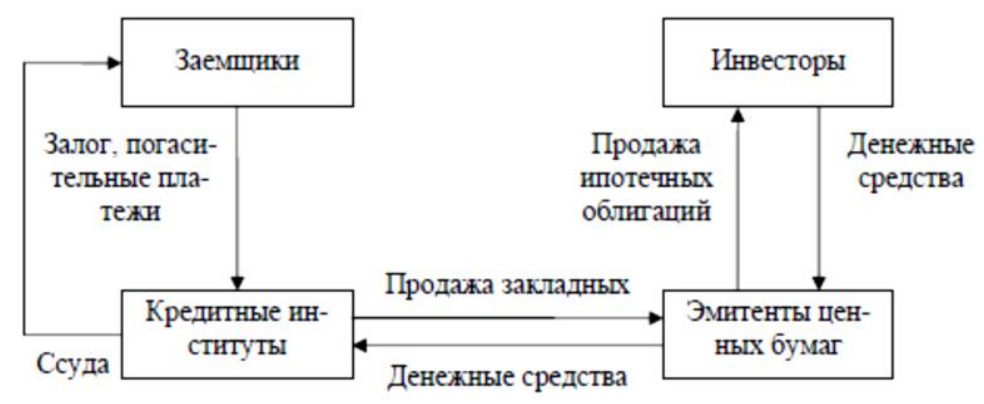

Рисунок 1. Схема двухуровневой системы ипотечного жилищного кредитования [4] 
кредит под залог недвижимости; специализированная организация, основная функция которой заключается в привлечении свободного капитала с целью его последующего реинвестирования в ипотечные кредиты; инвесторы, приобретающие ценные бумаги по ипотеке.

В настоящее время ипотечные ставки в США являются одними из самых низких в мире - от $3 \%$ до $7 \%$. На размер ставки влияет состояние экономики, политические изменения и другие факторы. В период с 2016 по 2017 годы ставка выросла на $0,7 \%$ в связи с выборами президента и составила $4,5 \%$. Повышение считается значительным, но количество заявок по ипотеке весной 2017 года достигло рекордных значений. Согласно последнему обзору ипотечного агентства Freddie Мас, ставки по ипотечным кредитам в США в начале августа 2018 года установили максимум за 2018 год - 4,6\%. Увеличение процента по ипотеке в паре с отсутствием доступных предложений привело к падению продаж на рынке недвижимости.

В системе ипотечного жилищного кредитования США функционирует развитая ипотечная инфраструктура, в частности, созданы специальные структуры - национальная ипотечная ассоциация - Federal National Mortgage Association - («Fannie Mae», 1938). Организация и обслуживание вторичного рынка ипотечного кредитования в США, поручена государственному учреждению Federal National Mortgage Association («Freddie Mac», 1970). Это исторически спонсируемые государством предприятия, акции которых котируются на фондовом рынке США. «Fannie Mae» и «Freddie Мас» скупали пакеты ипотечных займов у банков и секьюритизировали их, выпуская ипотечные облигации. Тем самым банкам оказывалась помощь в выдаче ипотечных займов, что давало возможность населению США получать кредиты на покупку недвижимости. «Fannie Mae» и «Freddie Mac» за- нимали денежные средства по низким ставкам и зарабатывали на комиссии за принятие кредитного риска. Банки, в свою очередь, получали приток ликвидности на развитие ипотечных операций в различных экономических условиях. Это создает возможность непрерывного обслуживания платежей по ценным бумагам, обеспеченным ипотечными кредитами.

Выделим основные преимущества двухуровневой модели ипотечного жилищного кредитования: инструменты финансового рынка обеспечивают привлечение в сферу жилищной недвижимости значительный объем инвестиций; низкая стоимость ипотечных кредитов за счет привлечения с фондового рынка дешевых финансовых ресурсов; распределение рисков финансово-кредитных операций между участниками системы ипотечного жилищного кредитования. Однако открытость и ориентированность на рынок капитала делает эту модель уязвимой от финансовых кризисов. Поэтому применять американскую модель ипотечного жилищного кредитования могут только развитые страны с устойчивой экономикой.

Одноуровневая модель ипотечного жилищного кредитования распространена в странах Европы (Австрии, Германии, Дании, Франции и др.). При одноуровневой модели ипотечного кредитования функции кредитора и инвестора выполняет один субъект, то есть специализированное кредитное учреждение, выдавшее ипотечный кредит, самостоятельно осуществляет выпуск и реализацию ипотечных ценных бумаг (см. рисунок 2).

Среди крупных банков Германии по выдаче ипотечных кредитов можно назвать «Bayerishe Hypo-und Vereinsbank AG», «Commerzbank AG», «Deutsche Bank AG», «Dresdner Bank AG» и др. Процентные ставки по ипотечным кредитам с 2013 по 2018 годы снизились в среднем с 2,77 до 1,89\%. Выгодные условия кредитования стиму-

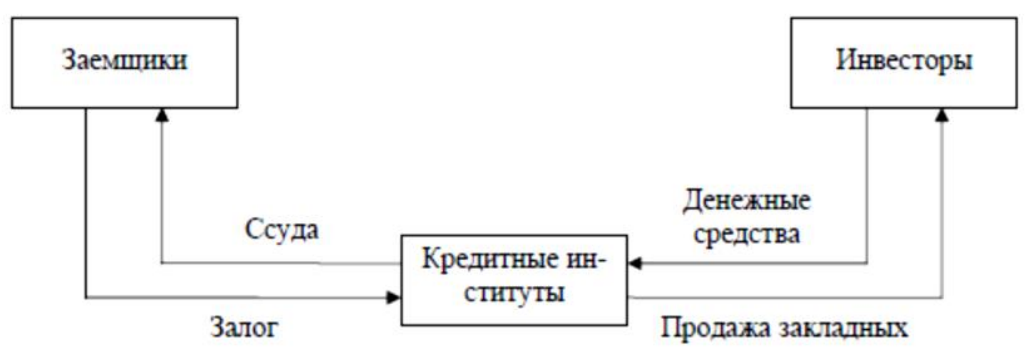

Рисунок 2. Схема одноуровневой системы ипотечного жилищного кредитования [4] 
лируют спрос. Также наиболее привлекательные условия по ипотеке предоставляются в Швейцарии $-1,42 \%$, Финляндии -1,53\%; Швеции- $1,87 \%$, Словакии $-1,92 \%$, Чехии $-1,99 \%$. Для сравнения - в Японии процентная ставка по ипотеке составляет в 2018 году - 1,21\%, во Франции $2,09 \%$, в Испании $-2,27 \%$, в Великобритании $3,24 \%$; в США $-4,6 \%$, в России - 9,5\%.

Отметим, что ипотечный жилищный кредит характеризуется особенностями, вытекающими из его сущности, а именно: долгосрочный характер, который ведет к необходимости его рефинансирования; ипотечное жилищное кредитование и рефинансирование тесно взаимосвязаны, осуществляются одновременно на рынке банковских услуг и фондовом рынке; залог в виде жилой недвижимости, выступающий обеспечением ипотечного жилищного кредита, подвержен колебаниям цен на недвижимость в долгосрочной перспективе и вызывает сложности при его реализации в случае неисполнения заемщиком обязательств перед кредитором.

Официально в России за основу принята двухуровневая модель ипотечного жилищного кредитования, построение которой способно решить многие проблемы и повысить доступность жилья в нашей стране.

Анализируя региональный уровень системы ипотечного жилищного кредитования, следует отметить, что доля Ростовской области составляет 2,1\% от общероссийского объема выданных ипотечных кредитов. В 2013-2018 годах в Ростовской области наблюдается рост объемов и количества выданных ипотечных кредитов.

Средняя ставка по ипотечным жилищным кредитам в Ростовской области снизилась с 12,5\% в 2016 году до 10,7\% в 2017 году и до 9,6\% в 2018 году. В 2018 году в Ростовской области средний доход семьи ипотечного заемщика со- ставляет 71,9 тыс. руб. в месяц, платеж по ипотеке $-21,8$ тыс. руб. У заемщиков уходит в среднем 14,9 лет на погашение ипотеки. Средний размер ипотечного кредита на 01.01.2019 года составил 2,341 млн. руб. [3].

На рынке ипотечного кредитования в Ростовской области работают: региональные банки, филиалы иногородних банков и банки других регионов. Основной тенденцией ростовского рынка ипотечного жилищного кредитования выступает рефинансирование процентной ставки по кредиту, доля которого $-35-40 \%$ от общего объема ипотечного жилищного кредитования. Снижение общих процентных ставок дает возможность заемщику сэкономить до $25 \%$ ежемесячного платежа.

По объёмам предоставленных в 2018 году ипотечных жилищных кредитов в Ростовской области лидируют такие банки, как Сбербанк ((Юго-Западный банк Сбербанка России - доля 55\% от объема выданных ипотечных жилищных кредитов), региональный банк ЦентрИнвест (17\%) и Группа ВТБ (13\%). На долю банков ДельтаКредит, Райффайзенбанк, Уралсиб, Возрождение, банк Открытие, Альфа банк и др. приходятся остальные $15 \%$ рынка ипотечных жилищных кредитов Ростовской области. В целом доля региональных банков на рынке ипотеки Ростовской области выросла до 20\%. При этом доля региональных банков в просроченной задолженности по ипотечным жилищным кредитам снизилась до 6\% [2].

Охарактеризуем кратко деятельность лидеров финансового рынка Ростовской области Юго-Западного банка Сбербанка России, банка ЦентрИнвест, Группы ВТБ.

Юго-Западный банк Сбербанка России увеличил в 2018 году объемы жилищного кредитования в Ростовской области на $91 \%$ по сумме в

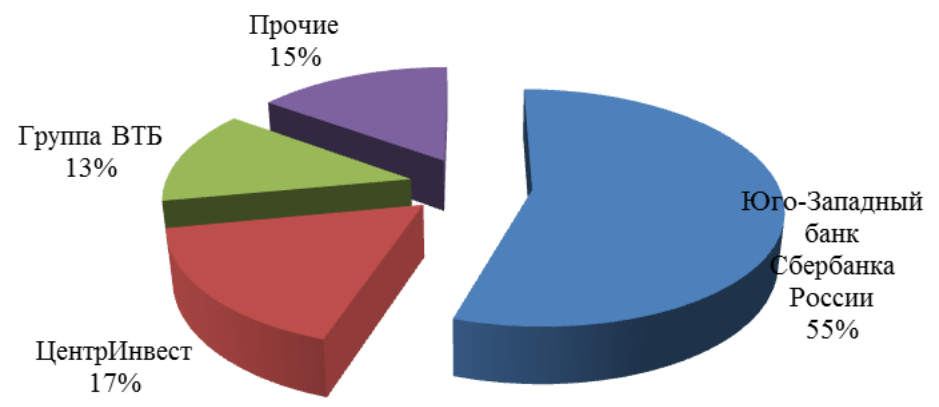

Рисунок 3. Кредитные организации, предоставляющие ИЖК, на рынке Ростовской области в 2018 г., ед. [составлено автором по материалам исследования] 
сравнении с аналогичным периодом 2017 года. Усиление позиций банка во многом произошло благодаря положительной конъюнктуре рынка, а также качественному развитию комплекса ипотечных сервисов и продуктов Сбербанка. Примером может служить платформа для поиска и покупки недвижимости в ипотеку «ДомКлик», количество пользователей которой в России уже превысило один млн. чел.

Банк Центр-Инвест увеличил в 2018 году объемы жилищного кредитования на $55 \%$ по сумме в сравнении с 2017 годом. Ипотечное жилищное кредитование в Центр-Инвесте характеризуется довольно выгодными условиями: отсутствие обязательной страховки и максимальной суммы кредита; нет скрытых комиссий; возможность подобрать программу с фиксированной либо плавающей процентной ставкой.

Центр-Инвест предлагает физическим лицам несколько вариантов ипотечных кредитов, которые можно получить в рамках рефинансирования. Например, семьи, в которых с 2018 по 2022 годы родится второй или третий ребёнок, могут претендовать на ипотеку по льготным условиям. Заем выдаётся на срок до 20 лет по ставке от $6 \%$, с первоначальным взносом от $20 \%$. Предельная сумма займа - до 3 млн. руб.

Возможно рефинансирование ипотеки стороннего банка, выданной на покупку жилья на первичном рынке недвижимости (т.е. до того, как жилое помещение было сдано в эксплуатацию). В таком случае разрешается взять от 300 тыс. руб. с первоначальным взносом от 20\% под ставку от 9\%. На аналогичных условиях можно рефинансировать ипотеку, выданную на покупку недвижимости на вторичном рынке, однако там первоначальный взнос меньше - от 10\% и выше. Кроме того, Центр-Инвест проводит перекредитование ипотеки сторонних банков, которая была выдана на строительство жилья. Выдаётся сумма от 300 тыс. руб. на срок до 20 лет под ставку от 10,5\%. В качестве первоначального взноса придётся внести минимум $10 \%$.

Группа ВТБ в Ростовской области увеличило объем ипотечного жилищного кредитования в денежном выражении на 77\% в 2018 году. При этом около $45 \%$ объема ипотечного кредитования пришлось на новостройки, 55\% - на готовое жилье. Каждая шестая заявка была реализована по программе рефинансирования, доля которой в общем объеме составила $16 \%$.
По данным банка, на ситуацию в целом повлияло снижение процентной ставки по ипотечным кредитам. Отметим, что снижение процентных ставок по ипотечному жилищному кредитованию не решает проблему обеспеченности населения жильем. Снижение ставок может привести к тому, что на получение кредита будет претендовать больше заемщиков, увеличение спроса повлечет за собой рост цен, что может сделать жилье менее доступным.

Можно выделить следующие направления совершенствования ипотечного жилищного кредитования в контексте концепции устойчивого развития национальной экономики:

1) разработка и развитие программ социальной ипотеки, рассчитанной на отдельные социально-незащищенные категории граждан с невысоким доходом с привлечением корпоративных соинвесторов;

2) разработка мероприятий по стимулированию строительства доступного жилья экономического класса и жилья бизнес-класса, например, путем снижения банковских ставок кредитования застройщиков и страхования рисков заемщиков строительного сектора в условиях безальтернативного проектного финансирования - отмены «долевого строительства»; упрощения процедур выделения земельных участков под строительство жилья; софинансирования подключения к коммуникациям и др.;

3) усиление работы по привлечению долгосрочных инвестиций путем эмиссии ценных ипотечных бумаг;

4) развитие ипотечных программ с использованием накопительных схем;

5) дальнейшее развитие рынка ипотечных ценных бумаг - ипотечные ценные бумаги, проданные инвестору, являются источником финансирования новой ипотеки;

6) развитие digital-процессов обслуживания получения ипотечного жилищного кредита и регистрации сделок - «электронная ипотека» [1].

Реализация мероприятий по названным направлениям позволит более успешно решать задачу обеспечения жильем большинства населения области; создать условия для развития строительной и сопряженных с ней других отраслей региона; насытить первичный рынок жилой недвижимости, а также укрепить финансовую систему. 


\section{Библиографический список}

1. Иванова Д.Г. Инновационные инструменты развития регионального рынка ипотечного жилищного кредитования// X Международная научно-практическая конференция «Инновационное развитие российской экономики» - Москва: ФГБОУ ВО «РЭУ им. Г.В. Плеханова», 2017.- 312 с.

2. Ипотечное кредитование в цифрах. Статистика выдачи ипотечных кредитов URL: http://rusipoteka.ru/ ipoteka_v_rossii/ipoteka_statitiska/ (дата обращения 02.11.2019)

3. Показатели рынка жилищного (ипотечного жилищного) кредитования URL: http://www.cbr.ru/statistics/ UDStat.aspx? Month=01\&Year=2019\&TblID=4-6 (дата обращения 28.10.2019)

4. Синчугов Б.К. Модели ипотечного жилищного кредитования: отечественный и зарубежный опыт // Международный журнал прикладных и фундаментальных исследований. - 2016. - № 7-2.- C. 298-302; URL: https://applied-research.ru/ru/article/view?id=9815 (дата обращения: 12.12.2019). 